\title{
Numerical Simulations of Fire Resistance Tests on Steel and Composite Structural Elements or Frames
}

\author{
J. B. SCHLEICH \\ ARBED-Research, Luxembourg \\ J. C. DOTREPPE and J. M. FRANSSEN \\ National Fund for Scientific Research \\ University of Liege, Belgium
}

\section{ABSTRACT}

A computer program for the analysis of steel and composite structures under fire conditions is presented. It is based on the finite element method using beam elements with subdivision of the cross section in a rectangular mesh. The structure submitted to increasing loads or temperatures is analyzed step-by-step using the Newton-Raphson procedure. The therma1 problem is solved by a finite difference method based on the heat balance between adjacent elements. Comparisons are made between full scale tests on steel and composite structural elements and frames and the results given by the numerical simulations. The agreement appears to be quite good. Furthermore are discussed the new possibilities given by this numerical computer code.

\section{INTRODUCTION}

When a fire breaks out in a building, heavy damage to people and property will occur if the structural part of the building happens to collapse. A good fire resistance of the loaded structure is a non sufficient but necessary condition to preserve the integrity of a building, to allow the rescue of occupants and to give the fire-brigade the opportunity of an effective intervention.

The first way to determine the fire endurance of a structural element has been the full scale test in furnace. In Europe, the standard fire resistance test according to ISO-834 has been used quite intensively and, in many countries, it is still the only legal way to classify structural elements regarding their fire resistance. Nevertheless, a test procedure has several shortcomings concerning the maximum size of the element, the avallable loading capacities, the heating system and the restraint characteristics. A full scale test is long to prepare, expensive to perform and gives one result for particular values of the parameters. Furthermore, the behaviour of one single column or one single beam in a furnace will not necessarily give a good idea of the behaviour that the element would have if it was a part of the whole structure.

Therefore the need for analytical models of thermal and structural response has grown intensively. Considerable progress has been made in the development of simple analytical methods, particularly for steel and composite elements $[1,2,3,4]$ and in several countries the practical evaluation of the fire resistance can now be made through these simplified 
calculation models. Unfortunately, this type of method does not apply to al1 cases and it has severe Iimitations when more parameters have to be taken into account in order to simulate real situations.

During the last decade a considerable amount of work has been performed in the Department of Bridges and Structural Engineering of the University of Liège in order to develop models for the analysis of the structural behaviour under fire conditions. Most of the work has been conducted in the field of structural analysis for steel and mainly concrete structures. Many numerical examples have been performed using the model developed and practical conclusions have been drawn [5].

Presently new developments are realized at the University of Liège on steel and composite structures within a C.E.C. research [6] introduced by ARBED. The aim of this paper is to present some informations on the program itself, to show some results which have already been obtained and to discuss the limitations, the possibilities of the program and the applications that can be expected from now on. Since this work is still in progress, the present paper has to be considered as a status report on this research program [7].

\section{THE PROGRAM CEFICOSS}

CEFICOSS stands for " Computer Englneering of the FIre resistance for composite and steel Structures". Indeed, though the program is suitable for reinforced concrete structures, it has essentially been developed for and applied to composite and steel structures.

\section{Static Calculations}

The program is a finite element program using a beam element with two nodes and six degrees of freedom, two translations and one rotation at each node. The shear displacements and the shear energy are not considered; the Navier-Bernoulli hypothesis is assumed. In one element, the stiffness properties and the internal forces are calculated in two cross-sections. Thus, the stiffness matrix of the element results from a Gaussian integration along the longitudinal axis. The cross section of this beam element is divided into subslices forming a rectangular mesh (Fig. 1). The kind of material, the temperature, the strain and the stress are different from one patch to another and the integrals on the cross section appearing in the stiffness matrix, the internal bending moments and centric forces are computed in a numerical way.

Stress-strain relations in the materials are non-linear and moreover are temperature dependent. In a structure submitted to fire loads, the materials are subjected to initial strains due to thermal effects $\left(\varepsilon_{t h}\right)$ and to creep effects $\left(\varepsilon_{c r}\right)$. Thus the stresses are caused by the difference between the total strains $\left(\varepsilon_{t o}\right)$, derived from the nodal displacements, and the initial strains:

$$
\sigma=\sigma\left(\varepsilon_{\sigma}\right)=\sigma\left(\varepsilon_{\text {to }}-\varepsilon_{\text {th }}-\varepsilon_{c r}\right)
$$

In this computer program, the creep strains are not explicitly taken into account, but have been considered indirectly in the stress-strain relationship. The strainhardening effect in the steel stress-strain relationship, which seems to be quite important, has been introduced in this computer code.

Due to the thermal effects, it may happen that the stress related strain $\left(\varepsilon_{\sigma}\right)$ grows up in the first minutes of the simulation and then finally 
decreases. These return effects of the stress related strains must be taken into account. It has been assumed that the unloading branch of a stress strain curve is linear and that the plastic part of the strain ( $\varepsilon_{p I}$ ) is not affected by a temperature variation (Fig. 2).

As the geometrical non-1inearities have to be taken into account, the equilibrium conditions, based on the principle of virtual work and leading to the stiffness matrix of the structure, are written in an incremental form. Moreover, when estimating the displacements from one time step to the following one, each finite element is assumed to be straight in the starting step. Thus, the up-dated Lagrangian description is applied.

Due to the high non linear character of the analyzed structures, a single step process would lead to important discrepancies. Thus, within each time step, an iterative process has to be used in order to eliminate the out-of-balance forces and to restore equilibrium. Two different kinds of non-linearities have to be considered: continuous non-linearities like the variation of the material properties in function of temperatures, and discontinuities like the cracking of concrete. Due to these last discontinuities some sudden changes occur in the stiffness matrix which has to be reformulated at each step during the iterative process, consequently leading to a Newton-Raphson process.

\section{Thermal Problem}

A real fire in a building being a very complexe phenomenon, it is not easy to take into account every possible parameter able to influence the fire consequences. In the fire resistance tests, the gas temperature in the furnace is given as a function of time and, in fact, is the main parameter of the test.

The convection process between the air and the structure is obvious and leads to a boundary condition of the Newton type. Very important is the radiative mode of heat transfer which takes place between the walls of the furnace and the structural element. Thus, the temperature of the inside faces of the furnace and the temperature at the surface of the element should appear in the mathematical expression of that exchange. Yet, the temperature of the furnace walls is not directly known, but depends on the characteristics of every furnace. Therefore the gas temperature is considered instead of the temperature of the furnace walls. In fact, the approximation is not too bad because the walls of the furnace have a low thermal conductivity. The thermal gradient existing close to the inside face of the wall being very high, the temperature of the inside surface will be close to the gas temperature. Consequently, the boundary condition at the structural element surface is given by:

$$
\begin{aligned}
& \mathrm{Q}=\alpha\left(\mathrm{T}_{\mathrm{G}}-\mathrm{T}_{\mathrm{S}}\right)+\sigma^{*} \cdot \varepsilon^{*}\left(\mathrm{~T}_{\mathrm{G}}{ }^{4}-\mathrm{T}_{\mathrm{S}}{ }^{4}\right) \\
& \mathrm{T}_{\mathrm{G}}=\text { gas temperature (given as a function of time) } \\
& \mathrm{T}_{\mathrm{S}}=\text { temperature at the element surface (to be calculated) } \\
& \alpha=\text { coefficient of convection heat transfer (experimental value) } \\
& \varepsilon^{*}=\text { resultant emissivity (experimental value) } \\
& \sigma^{*}=\text { Stefan-Boltzmann constant } \\
& \mathrm{Q}=\text { heat flow through boundary }
\end{aligned}
$$

The equations of the transient heat flow inside the structural element are well known. These equations are solved by a finite difference method 


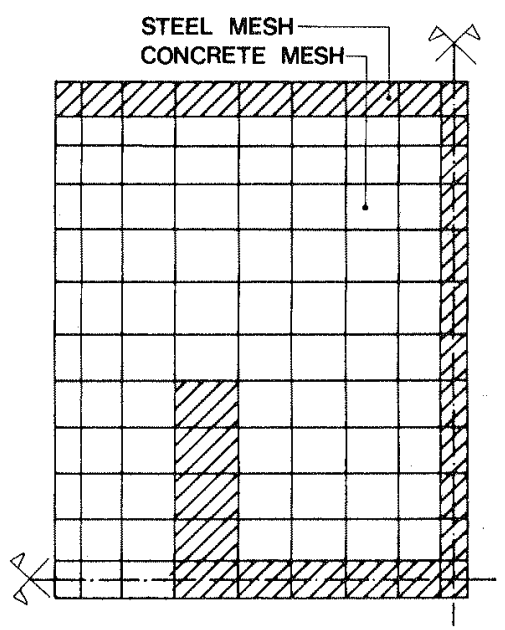

Fig. 1: Cross section of beam element with concrete and steel mesh.

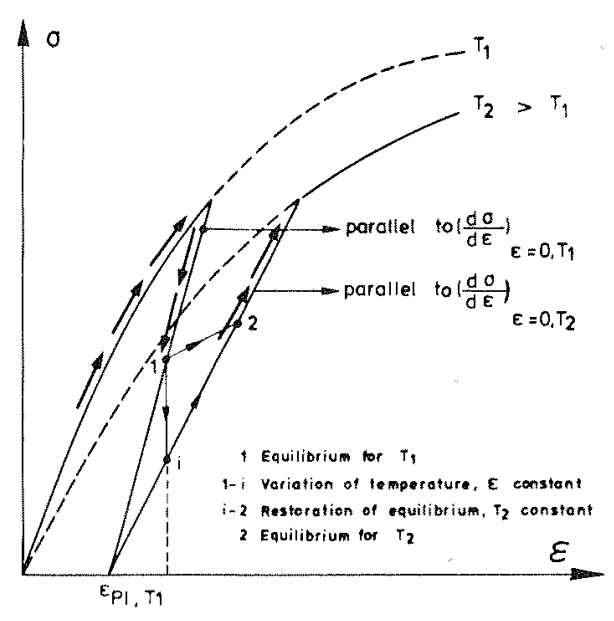

Fig. 2 : Return effect of stress related strain in function of temperature increase.

\section{$Q_{I}+Q_{I I}+Q_{I I I}+Q_{I V}=$}

$C \cdot \rho \cdot \Delta T \cdot V+Q$ evaporation

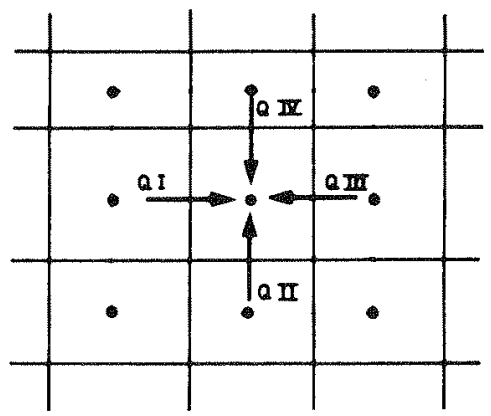

Fig. 3 : Heat balance between adjacent patches.

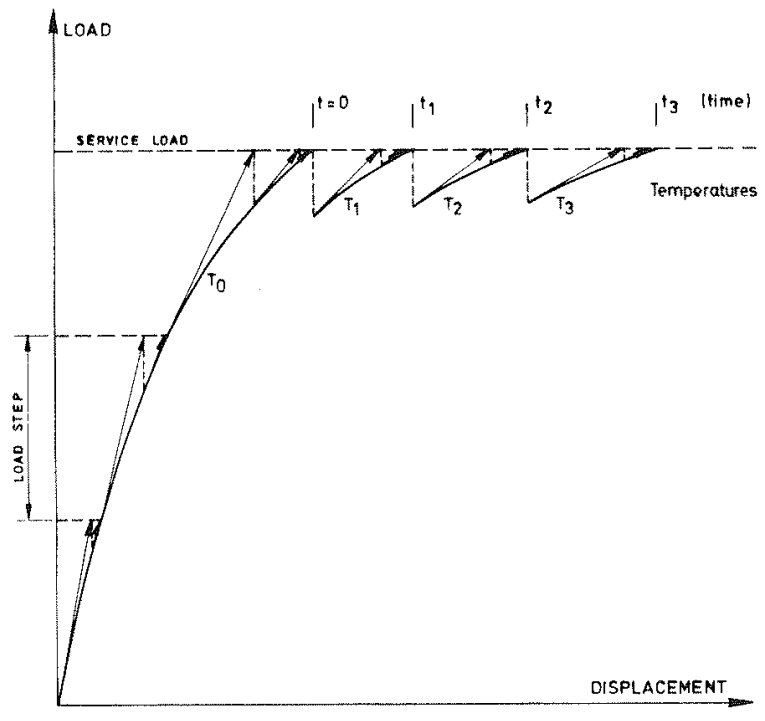

Fig. 4: Alternative thermal and static calculations at time $t$ in order to restore equilibrium under simultaneous action of the service load and the temperature increase. 
based on the heat balance (Fig. 3) between adjacent patches which moreover are identical to those of the structural analysis.

The main advantages of this method are:

- The equations have an immediate physical meaning so that $f . i$. the evaporation effect of moisture in concrete is easy to be simulated (Fig. 3).

- This method is explicit. The values of the temperature at a given time are obtained explicitly at the end of the previous time step. Furthermore, only $\mathrm{n}$ equations with one unknown per equation ( $n$ being the number of nodes of the mesh) have to be solved at each time step, whereas an implicit method would lead to a system of $n$ equations with $n$ unknowns per equation.

The main disadvantage of an explicit method lies in the fact that, for stability and precision reasons, a criterion relating the time step to the patch width must be satisfied. Due to the high thermal conductivity of steel, the thermal time step will be only about some seconds. It must be noticed that the arrangement of the program and the fact that the structural response of the structure must be calculated more or less every minute, do not allow at any rate to take profit of too long a time step which would have been obtained in case of an implicit analysis of the thermal problem.

\section{Program Flow Chart}

The solution principle is illustrated in figure 4 for a system with one degree of freedom. At ambient temperature, the load is applied step by step. After each load step, the equilibrium of the structure must be restored by the Newton-Raphson process. When the service load has been reached, it is kept constant all through the following fire simulation. In the cross section the temperatures of every patch are then calculated with a short time step derived from the stability condition mentioned previously. When the simulation of the fire test has reached a certain time of about one minute, the thermal analysis is stopped. Now the static part of the program calculates the displacements of the structure for the temperatures calculated at this time. Here again a Newton-Raphson process takes place in order to restore equilibrium.

This procedure composed of alternative thermal and static calculations goes on, up to the moment where equilibrium can no more be obtained. This moment is identical to the ultimate fire resistance time of the analysed structural element.

\section{RESULTS OF FIRE TESTS}

A lot of real tests have been performed in the last years, the results of which are available. Some of these fire resistance tests have been used during the development phase of this numerical software.

In that respect the structural behaviour of a reinforced concrete continuous $T$ beam on three supports has been analysed and the theoretical results have been compared with test results obtained at the Technical University of Braunschweig $[5,8]$. The loading and heating systems are presented in figure 5. The beam is loaded and heated unsymmetrically. The thermal program is applied according to the standard Iso temperature-time curve. The variation of the bending moment on the centric support of the $\mathrm{T}$ beam analysed here, is represented in figure 6. After approximately one hour the bending moment tends to become constant, which corresponds to the formation of a plastic hinge on the centric support. It can be observed that there is a good agreement between theoretical and experimental results. The corresponding 

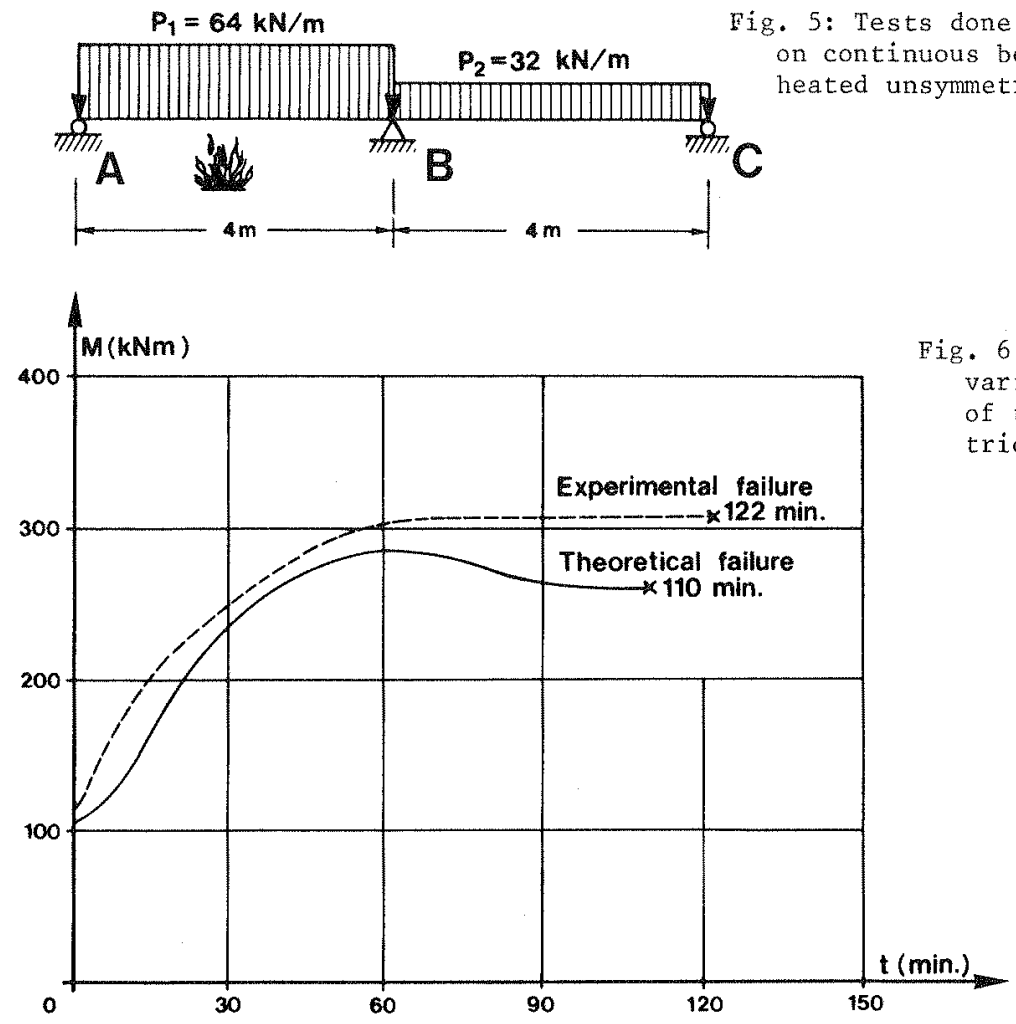

(kNm)

Fig. 7: Evolution of the beam bending moment diagram from cold loading up to the failure under fire action.

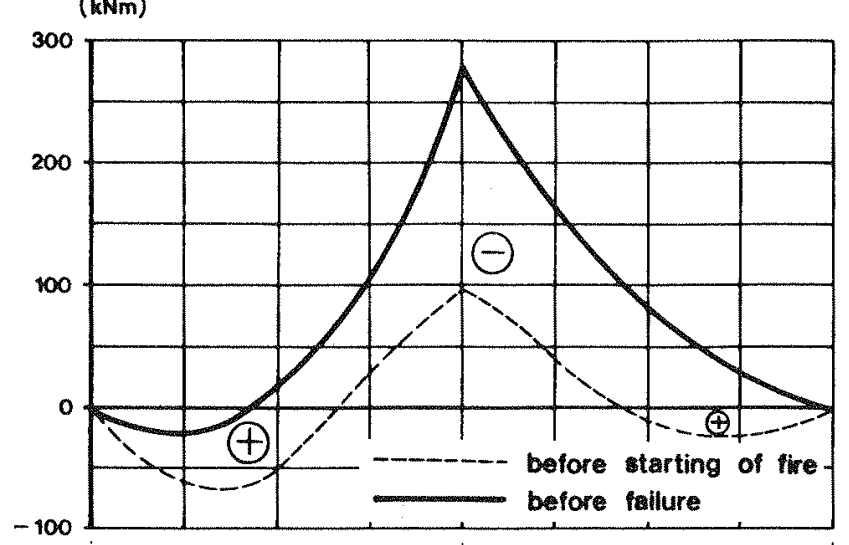
on continuous beams loaded and heated unsymmetrical1y [5, 8]. 
evolution of the bending moment diagram is indicated in figure 7 , showing the important redistribution of internal forces due to the thermal gradient. Before failure the diagram has only negative zones, except on the left hand side of the heated and most loaded span. This explains the failure mechanism represented in figure 8 .

In order to verify the simulation results given by CEFICOSS and to estimate with greater accuracy the values of certain fundamental physical parameters, it was decided to perform new series of real fire tests based on the ISO-834 heating curve. Thus a better comparison was guaranteed between test and simulation results and most interesting informations got available on a new type of composite structure developed by ARBED [7].

\section{Tests on Columns}

At the University of Gent [9] two columns were tested under longitudinal load with an eccentricity of $180 \mathrm{~mm}$ around the weak axis. The steel profile in both tests was the heavy American wide flange shape W $14 \times 16 \times 500$. Column 1.1. was not protected against direct fire action. This test made clear that a high massivity - the section factor $F / V$ of this steel profile was $27 \mathrm{~m}^{-1}-$ provides a good fire resistance even to bare steel profiles. Only numerical softwares, giving the temperature gradient through steel thickness, are able to predict correctly the behaviour of thick bare steel elements. The fire test gave a resistance time of 46 minutes, whereas the simulation by CEFICOSS gives 45 minutes.

Column 1.2. composed of the same profil as column 1.1 , was loaded in exactly the same way. But column 1.2. was protected by an intumescent fire retardant coating [9] which contributed to give a resistance time of 145 minutes in the fire test. It has been shown that the program CEFICOSS is able to simulate correctly the behaviour of such a structure, provided that the thermal characteristics of the paint layer can be measured: the calculated fire resistance amounts to 134 minutes $(92 \%)$. The final thickness of the swollen intumescent coating has been measured after the test and introduced as a constant for the whole fire simulation. The value of the thermal conductivity has been given by the producer of the coating.

Two composite columns of the type AF30/120 were tested in Gent [9]. AF is a new type of composite cross section developed by ARBED [2,3] and is composed of a rolled H-profile concreted between the flanges. This concrete contains longitudinal reinforcing bars which contribute to support loads. These columns were centrically loaded and the buckling occured around the weak axis of the stee1 profile. Colum 1.3. which had no further protection on the exterior visible faces of the steel flanges, collapsed in the fire test only after 116 minutes, whereas the numerical simulation predicted a fire resistance time of 114 minutes.

Column 1.15. was identical to the previous one, with the exception of the steel flanges of the profile which were protected by a dry insulation layer of $25 \mathrm{~mm}$ thickness. The thermal properties of this insulation were not quite exactly known for higher temperatures. This could explain the slightly greater difference between the measured fire resistance time of 189 minutes and the value of 162 minutes $(86 \%)$ obtained by the CEFICOSS simulation.

The special cross-section column 1.4. (see fig. 9,a) behaved quite good in the fire test [9], as the resistance time attained 172 minutes, though four visible steel flanges were exposed directly to the fire action. This 
Fig. 9: Special composite cross

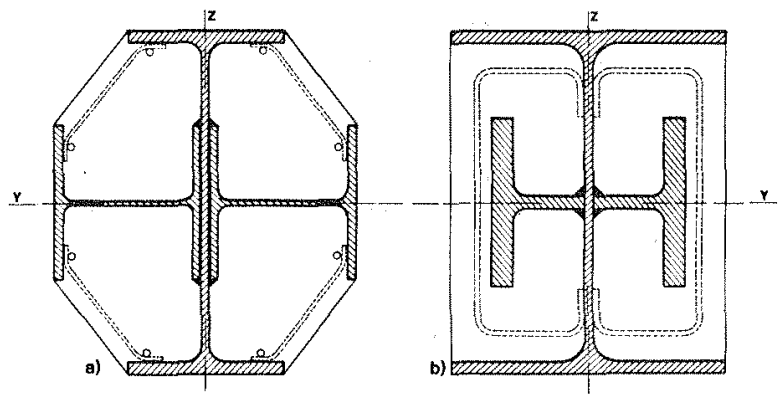
sections, exclusively composed of rolled profiles, developed for the purpose of columns supporting centric loads and bending moments around $\mathrm{Y}$ or/and $\mathrm{Z}$ axis.

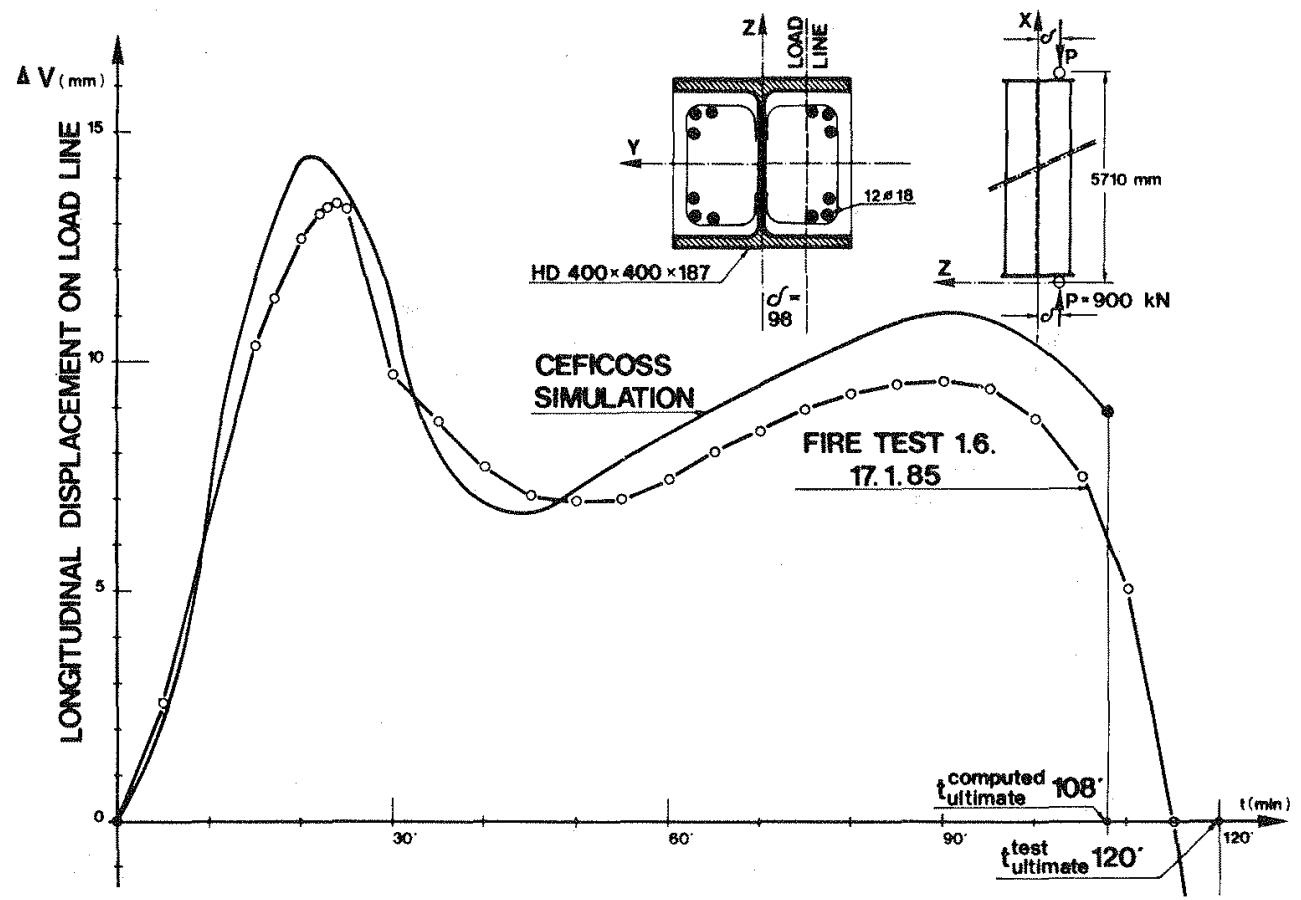

Fig. 10: Calculated and measured longitudinal displacement $\triangle V$ of a composite AF column, supporting the eccentric load $P$ during the fire test $[7,10]$

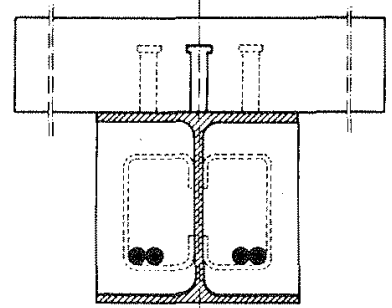

Fig. 1I: Composite beam cross section 
column was composed of three rolled H-profiles, welded together and concreted between the flanges. The concrete of this octagonal cross section contained no reinforcing bars. CEFICOSS gave a fire resistance of 146 minutes (85\%).

Two columns of the type AF30/120 were tested at the University of Braunschweig [10], with a load eccentricity of $98 \mathrm{~mm}$ around the weak axis. Column 1.5. had a length of $3,74 \mathrm{~m}$ and collapsed in the fire test after 136 minutes, whereas the numerical simulation had given a fire resistance of 110 minutes. This difference is the worst numerical result we obtained.

Column 1.6. was identical to column 1.5. with the difference that it had a length of $5,71 \mathrm{~m}$ and that the load had been reduced. The fire test gave a resistance time of 120 minutes whereas the simulation by CEFICOSS predicted 108 minutes $(90 \%)$. Figure 10 shows the pretty good agreement between the calculated and measured longitudinal displacement of the column during fire action.

In order to allow higher bending moments around the weak axis, it is advantageous to replace reinforcing bars by $T$ profiles welded on the web of the main $\mathrm{H}$ profile. Figure $9 \mathrm{~b}$ presents such a cross section. Two columns of this type have been tested successfully in Braunschweig [10]. For column 1.7. f.i. the measured fire resistance time was 111 minutes, while the numerical simulation gave 114 minutes.

\section{Tests on Beams}

Four beams were tested in Gent [9]. They were composed of the AF composite profile supporting a concrete plate and fixed together by connectors welded on the upper flange of the steel profile (see fig. 11). In the test beam 2.11. the composite $T$ beam was simply supported on both ends. When applying the deflection criterion $\mathrm{f} \leqq \mathrm{J} / 30$ in order to define the fire resistance time, the comparison between the test result (171 minutes) and the simulation (149 minutes) appears to be quite good $(87 \%)$.

In the test beam 2.14., no connectors were placed between the AF profile and the covering plate. This was simply laid on the upper flange, had to be considered in the calculation of temperature distribution, but did not contribute to the static resistance of the lower AF cross section. Here again the fire resistance times measured in test ( 92 minutes) and computed by CEFICOSS (87 minutes) show a rather good agreement (95\%). Figure 12 gives the measured and simulated mid-span deflection of this composite beam.

The two composite beams 2.12 and 2.13 were tested with one end simply supported and the other fixed. In both cases a plastic hinge was formed close to the fixed end, which was confirmed by the numerical simulation.

\section{Tests on Frames}

One of the most interesting possibilities of CEFICOSS is the analysis of fire effect on frames. Of course, no furnace exists able to test a whole building under fire action. Yet, at the University of Braunschweig, the opportunity is given to test simple frames comprising one column and one beam. Thus, two frame-tests have been performed [11] confirming the numerical results given by the simulation program. The types of column and beam composing these two frames are shown on figures $9 \mathrm{~b}$ and 11 , whereas figure 13 shows the very good agreement between the measured and calculated horizontal displacement of the column pratically at mid-height. 


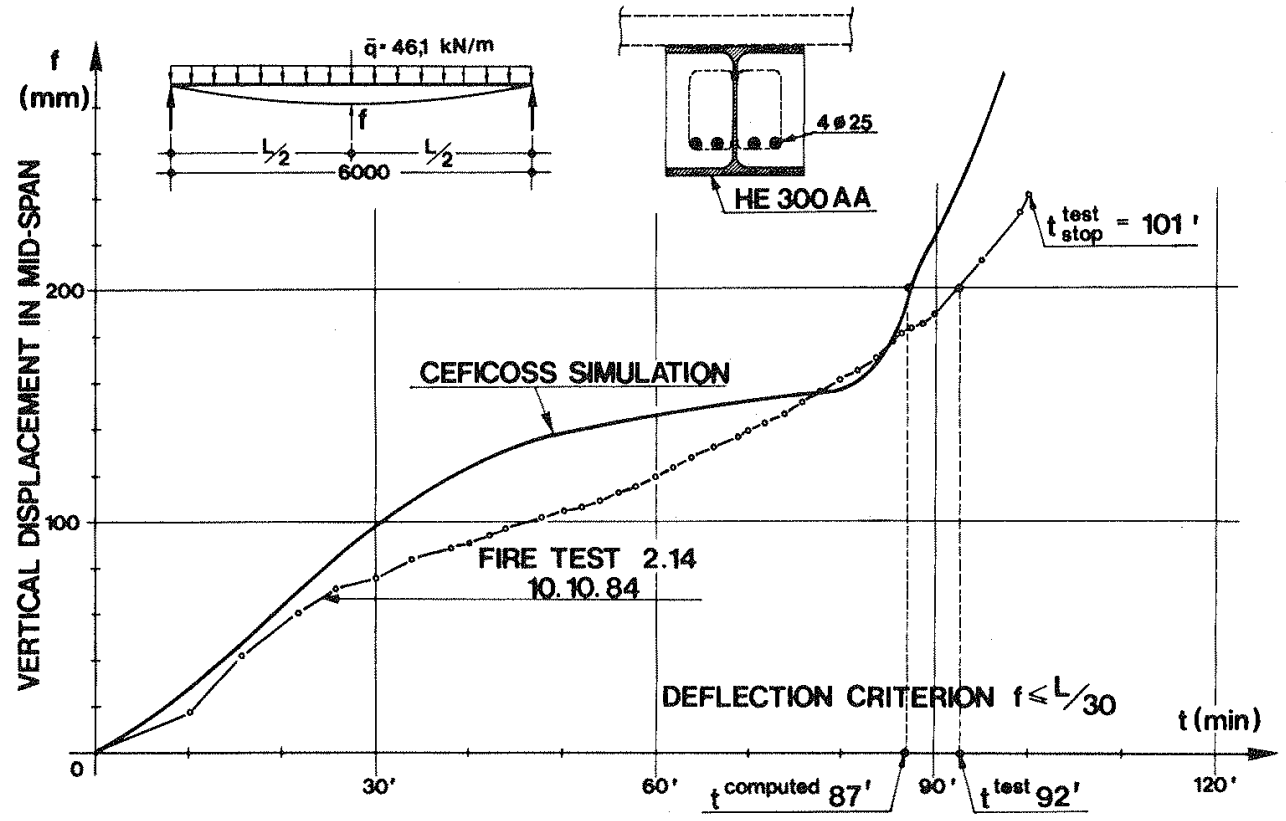

Fig. 12: Calculated and measured mid-span deflection $f$ of a composite AF beam during the fire test $[7,9]$.

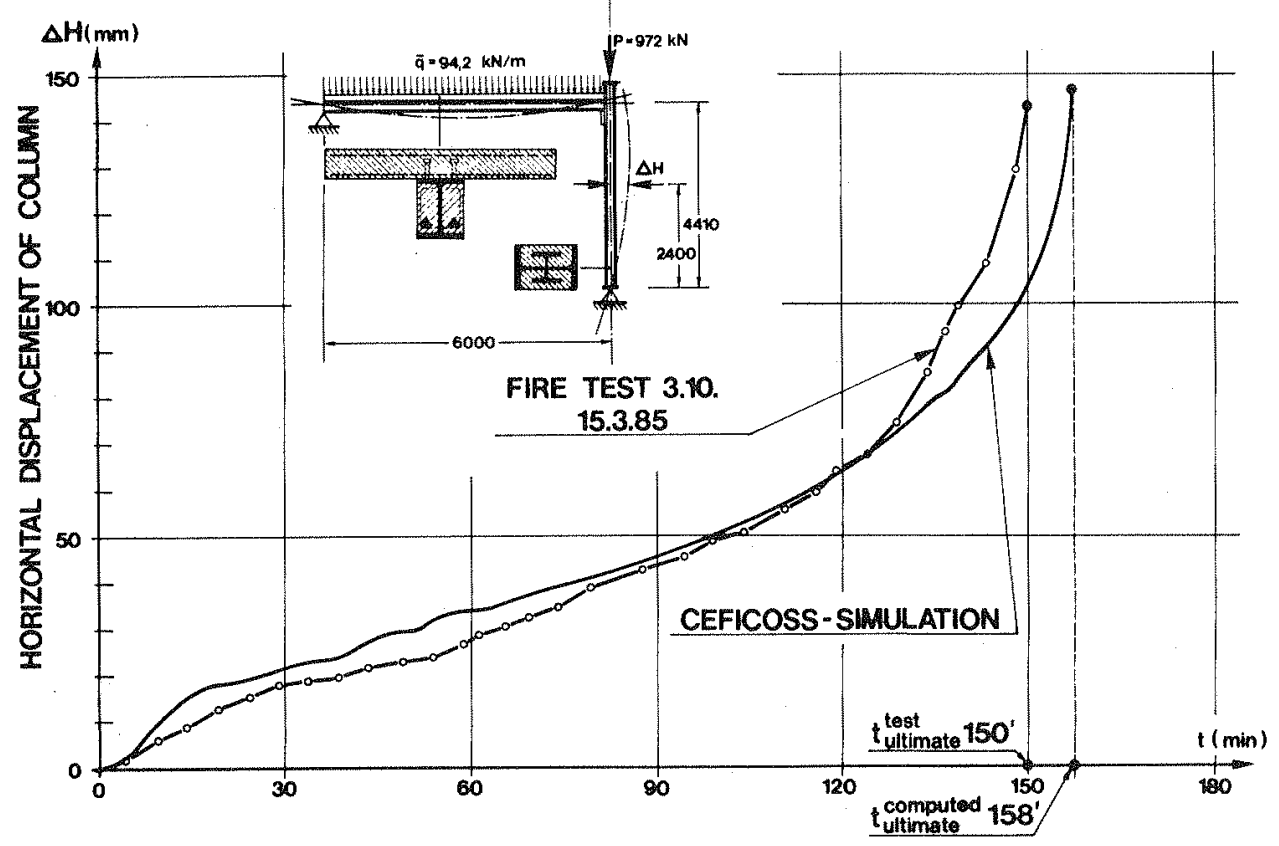

Fig. 13: Calculated and measured horizontal displacement $\Delta H$ of the frame column $3.10[7,11]$. 


\section{Conclusion on Test and Simulation Results}

Figures 10, 12 and 13 prove, and so do the stmilar curves drawn for the other tests, that a simulation by CEFICOSS is able to describe correctly the behaviour of a structure in a fire resistance test. Figure 14 is a graphic result presentation of all the tests that have been performed and simulated up to now. It can be noticed that the correspondence between theory and test results is quite acceptable [7].

\section{APPLICATTON FIELDS FOR CEFICOSS}

\section{Exploitation of Test Results}

A lot of structural parameters have an influence on the final result of a fire resistance test. If one single test is performed, it provides one result for one value of all the parameters and nothing can be said with precision about the way the test result would change in function of one of these parameters. Even two or three real fire tests with different column lengths, will hardly give enough information on the behaviour of the column regarding the general slenderness effect.

However a computer program like CEFICOSS, eventually calibrated by a given number of real tests, will be of great help for the solution of such problems. It is intended to use this program in order to examine the probletn of the simultaneous action of centric loads $(N)$ and bending moments (M) in a fire environment. In that respect practical design tables and diagrams for the different fire classes $F 60, F 90$ and F120, w111 be established for composite columns under $\mathrm{N} / \mathrm{M}$ interaction, and for composite beams under continuous load (see fig. 15).

Research

The most interesting application of this computer code may be the perspective offered for new research possibilities. It is intended not only to produce tables about the interaction between centric and bending forces, but it is also hoped to deduce some practical rules, allowing to take into account this phenomenon in a more simple manner. The correct behaviour of a whole structure in a fire can only be deduced from calculations based on a thermo-mechanical computer code 11ke CEFICOSS. In this way, it will now be possible to simulate numerically the tests which cannot be executed in practice, because of the limitation in size of the fire test installations or because of prohibitive costs.

From a more practical point of view a lot of investigations could be done and errors avoided, when developing new kinds of structures. The optimum fire design of a structure becomes now feasible for a reasonable price. For instance, the localization of reinforcing bars or structural tees could be chosen in function of the highest possible efficiency.

\section{Education}

Results of fire simulations could be presented on graphic screens. Thus, the variations of bending moments in hyperstatic structures, or the changes of compressive and tensile zones in cross sections and due to thermal effects could appear graphically. This would help to make lectures in fire resistance more understandable, attractive and efficient. 


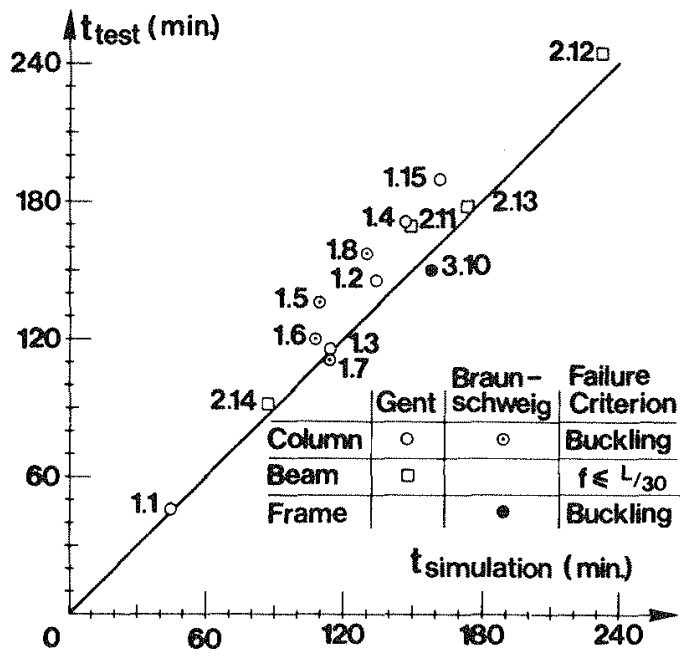

Fig. 14: Fire resistance times calculated by CEFICOSS simulation and measured on practical fire tests, of steel and composite structural elements $[7,9$ $10,11]$.

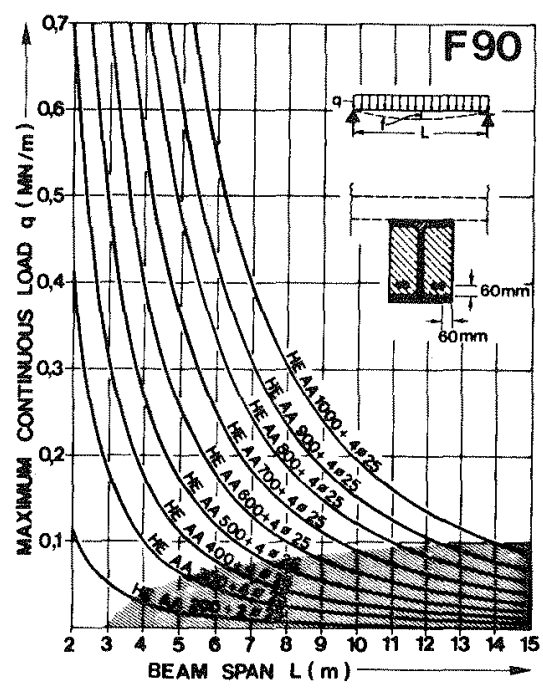

Fig. 15: Maximum continuous tota1 load q applicable to simply supported AF beams - having no connection to the concrete floor - in function of the beam span $L$ and for the fire class $\mathrm{F} 90\left(\sigma \mathrm{y}=355 \mathrm{~N} / \mathrm{mm}^{2}\right.$; $\left.\beta_{\mathrm{C}}=35 \mathrm{~N} / \mathrm{mm}^{2}\right)$. Steel sections belong to the rolled $\mathrm{H}$-profile series HEAA of ARBED.

\section{CONCLUSIONS}

It has been shown that the numerical software CEFICOSS is able to simulate in a correct way the structural behaviour in a fire resistance test and that it provides a pretty good estimation of the fire resistance time. This computer code will of course never be a substitute for real fire tests, because the rea1 test is the only way allowing to detect local problems such as spalling of concrete, lack of adherence to reinforcing bars, bad behaviour of welded joints or local buckling. CEFICOSS is to be considered as a new tool, which at last makes feasible a lot of new investigations allowing to improve seriously our knowledge on the behaviour of structures under fire conditions [12].

Indeed CEFICOSS is a general, thermo-mechanical numerical computer code for the analysis of column, beams or frames, composed of either bare stee1 profiles or steel sections protected by any type of insulation or even any types of composite steel-concrete cross-sections. Furthermore the ISO-834 standard fire curve, as well as any natural heating curve can be considered. 
This new computer code, allowing to determine the structural fire safety, corroborates the idea expressed by P.J. DiNENNO [13] that "The next evolution of the application of computers in the delivery of a fire safety system appears to be in the area of predicting fire resistance." This numerical tool becomes available at suitable time as B. BRESLER [14] says "... that the acceptable level of fire safety should be determined by calculation, just as it is for other types of loading." Structural fire safety could be provided for a precisely imposed level without paying for excessive fire protection; this means that substantial cost savings can be foreseen by using this new fire safety approach.

\section{REFERENCES}

[1] ECCS, TC3 - European Recommendations for the Fire Safety of Stee1 Structures - Elsevier; Amsterdam, Oxford, New York, 1983.

[2] JUNGBLUTH O., FEYEREISEN H., OBEREGGE 0. , - Verbundprofil- konstruktionen mit erhöhter Feuerwiderstandsdauer - Bauingenieur 55, 1980.

[3] SCHLEICH J.B., HUTMACHER H., LAHODA E., LICKES J.P., - A New Technology in Fireproof Steel Construction - Review Acier/Stahl/Steel Nr. 3, 1983.

[4] SCHLEICH J.B. - Fire Safety, Design of Composite Columns / International. Conference "Fire safe steel construction; practical design", Luxembourg, Apri1 1984 - Revue Technique Luxembourgeoise $\mathrm{Nr} .1$, 1985.

[5] DOTREPPE J.C. - Méthodes Numériques pour la Simulation du Comportement au Feu des Structures en Acler et en Béton armé - Thèse d'Agrégation de 1'Enseignement Supérieur, Université de Liège, 1980.

[6] DOTREPPE J.C., FRANSSEN J.M., SCHLETCH J.B. - Computer Aided Fire Resistance for Steel and Composite Structures - Review Acier/Stahl/Steel Nr. 3, 1984.

[7] ARBED-Research, Luxembourg / Department of BRIDGES and STRUCTURAL ENGINEERING, University of Liège, Belgium - REFAO/CAFIR; Computer Assisted Analysis of the Fire Resistance of Steel and Composite Stee1-Concrete Structures - C.E.C. Research 7210-SA/502, Technical reports 1 to 6 , $1982 / 1985$.

[8] WESCHE J. - Stahlbetondurchlaufkonstruktionen unter Feuerangriff Institut für Baustoffkunde und Stahlbetonbau, Technische Universität Braunschweig, 1974 .

[9] MINNE R., VANDEVELDE R., ODOU M. - Fire Test Reports Nr. 5091 to 5099 Laboratorium voor Aanwending der Brandstoffen en Warmte-overdracht, University of Gent, April to June 1985.

[10] KORDINA K., HASS R. - Untersuchungsbericht Nr. 85636 - Amtliche Materialprüfanstalt für das Bawesen, Technische Universität Braunschweig, Apri1 1985.

[11] KORDINA K., WESCHE J., HOFFEND F. - Untersuchungsbericht Nr. 85833 Amtliche Materialprüfanstalt für das Bawwesen, Technische Universität Braunschweig, Mai 1985.

[12] KLINGSCH W., SCHLEICH J.B. - Composite Steel-concrete Components, Present Time Acquirements and Future Possibilities - International Symposium "Steel in Buildings", Luxembourg, September 1985.

[13] DINENNO P.J. - Introduction/Guest Editor - Fire Safety Journal, Vo1. 9 No. 1, May 1985.

[14] BRESLER B. - Analytical Prediction of Structura1 Response to FireFire Safety Journa1, Vo1. 9 No.1, May 1985. 
